\title{
CORRIGENDUM
}

\section{Prenatal maternal immune activation causes epigenetic differences in adolescent mouse brain}

P Basil, Q Li, EL Dempster, J Mill, P-C Sham, CCY Wong and GM McAlonan

Translational Psychiatry (2014) 4, e455; doi:10.1038/tp.2014.104; published online 30 September 2014

Correction to: Translational Psychiatry (2014) 4, e434; doi:10.1038/ tp.2014.80; published online 2 September 2014

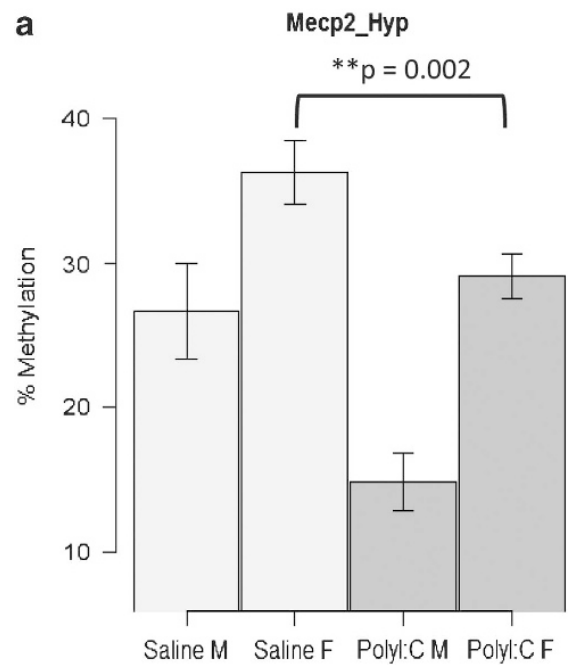

Following publication, the authors noticed that the error bars in Figure 1 showed Standard Deviation and not Standard Error of Mean as was stated in the legend. The corrected figure appears below.

b

Mecp2_Str

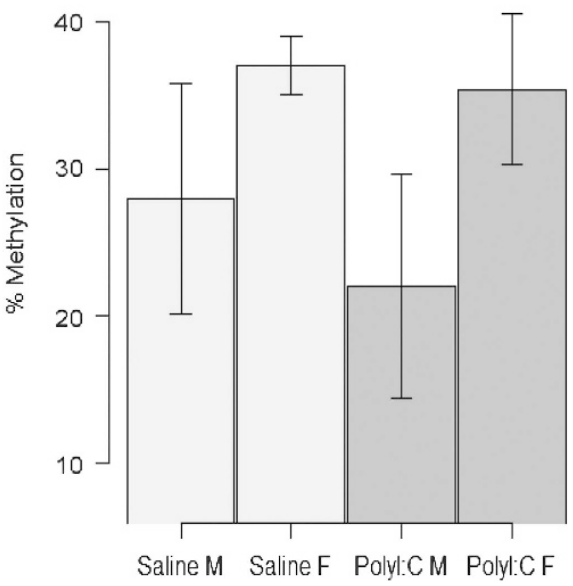

